\title{
THE FIRE RISK EVALUATION
}

\author{
Božo NIKOLIĆ ${ }^{1}$
}

\section{Research article}

Following the definition of risk as a combination of a probability for its happening and the
size of its damage, or, as a combination of the probability of a dangerous event, frequency
of the exposure and the size of the damage, a significant deviation away from the risk
function in the areas of the occupational safety and health (OSH) and the fire protection
(FP) has been noticed. In the mathematical expression of the fire risk according to the
de Gustav Purt method (Purt, 1972), risk factors identification was attempted. The basis
for this fire risk evaluation identification method within the OSH area was developed
by the authors from the HTS in Novi Sad (Nikolic and Gemovic, 2009a; Nikolic and
Gemovic, 2009b). This way accomplished a simultaneous calculation of all fire risks. The
structures' and their content's risks have been processed, as well as risks towards people in
the structures and firemen extinguishing the fire. Since the method has a communicative
character, the calculated risk values are easily and accurately measurable by comparison.
Danger, fire, fire protection, fire risk, risk evaluation.

\section{Introduction}

Even though the risk is defined in the same way in the areas of OSH and FP, their mathematical expressions are completely different and unrecognizably the same. In the area of FP, the fire risk evaluation is known for a long time, while various methods are developed. Many insurance companies investigated that topic, so the methods have been adjusted to the insurance system. That is why it is hard to recognize, in the fire risk expression, the elements of risk, the probabilities, the frequency and the size of the damage. The recognition of those elements is possible only in their detailed analyses (Nikolic, 2010).

\section{Materials and methods}

The risk evaluation in the area of OSH is a brand new area and an obligation created recently. Its specifics are connected to the consequences, which are endangering of the employees' health and life. This is borne in mind primarily during risk evaluation, so the synthesis of elements is not recommended. It is important to handle the risk data for every activity since only then can one react accordingly and influence risk reduction.

The risk reduction measures are also widely applicable. The FP measures are known in advance, so their choice and application is facilitated by using law regulations. These measures can be the same for different production processes, and their number is relatively small and, as mentioned before, they are fully known and have familiar application effects. In the OSH area, the measures are far more numerous and cannot be standardized, unified and generalized.

For example, if the automatization of the production process is the measure, that measure is different for every single production process. Automatization of the extinguishing process is the same or similar for very different processes.

One of the main tasks during the risk evaluation is to determine risks for all recognizable dangers to determine all risks. In the FP area, it makes sense to discuss property fire dangers, for the contents of structures and the structures themselves, the dangers for people who use those structures and firemen who extinguish fire in that structure. So, two out of three fire risks regard people. This is where the idea to try to use the same method came from. The used method is HTS's method, and it is applied during numerous projects in cooperation with the economy. Besides that, the application of this method is expanded via application in other areas (CCC) (Nikolic and Ruzic Dimitrijevic, 2009). All this pointed to the possibility of applying this method in the FP area (VV).

In the FP area, risk evaluation was conducted according the de Gustav Purt method (MM) (Purt, 1972), which determines the construction and especially content risk evaluation. The structure construction risk is a construction damaging danger, while the structure content risk is a danger to people and property in the structure. Equations that determine said risks are: 
1. The structure construction risk:

$$
R o=\left(P_{o} \cdot C+P_{k}\right) \cdot B \cdot L \cdot S / W \cdot R_{i}
$$

where $P_{0}$ is the structure content fire burden coefficient, $C$ is the structure content combustion coefficient, $P_{k}$ is the structure construction material fire burden coefficient, $B$ is the size and position of the fire sector coefficient, $L$ is the extinguishing start delay coefficient, $S$ is the fire sector width coefficient, $W$ is the structure's carrier construction fire resistance coefficient, $R_{i}$ is the fire risk reduction coefficient.

2. The structure content risk:

$$
R s=H \cdot D \cdot F
$$

where $H$ is the harm to people coefficient, $D$ is the harm to property coefficient, $F$ is the smoke effectiveness coefficient.

The OSH area uses HTS's method $(\mathrm{NN})(1,8)$ that determines risk:

1. For the production working place:

$$
R=V \cdot H \cdot F \cdot n
$$

2. For the working environment:

$$
R=f(x) \cdot H \cdot F \cdot n
$$

where $V$ is the probability of actions, $H$ is the size of the damage, $F$ is the frequency or duration of exposure to the danger, $n$ is the number of people simultaneously affected by the action coefficient, $f(x)$ is the protection state function.

\section{Results}

\begin{tabular}{|c|c|c|c|c|c|c|c|c|}
\hline $\mathbf{V i} / /(\mathbf{f}(\mathbf{x}))$ & 16.46 & 11.48 & 7.57 & 4.63 & 2.53 & 1.16 & 0.39 & 0.06 \\
\hline $\mathbf{P}_{\mathbf{o}} \cdot \mathbf{C}+\mathbf{P}_{\mathbf{k}}$ & 263.8 & 184 & 121.3 & 74.2 & 40.5 & 18.6 & 6.23 & 0.96 \\
\hline $\begin{array}{c}\mathbf{P}_{\mathbf{0}} \cdot \mathbf{C}+\mathbf{P K}_{\mathbf{~}} \cdot \\
\left.\mathbf{1 5}_{\mathbf{5}} \cdot \mathbf{5} \text { [MJ.m }^{-2}\right]\end{array}$ & 19.785 & 13.800 & 9.097 .5 & 5.565 & 3037.5 & 1395 & 467.25 & 72 \\
\hline
\end{tabular}

It is already mentioned that all risks must be determined. The risks in this article are:

- the structure construction risk,

- the property (the structure content) risk,

- the risk towards people in the structure and

- the firemen risk.

\section{The Fire Risk Evaluation}

From the structure construction fire risk equation,

$$
R o=\left(P_{o} \cdot C+P_{k}\right) \cdot B \cdot L \cdot S / W \cdot R_{i}
$$

The following coefficients will be kept:

- $P_{o}$ is the structure content fire burden coefficient,

- $C$ is the structure content combustion coefficient,
- $P_{k}$ is the structure construction material fire burden coefficient, MJ.m ${ }^{-2}$.

Other coefficients from that equation become measure factors and all can be applied since the risk calculated before their application will be highest. The risk will then present the probability for fire appearance (2), without the defined damage size and frequency.

$$
R o=V=4.68\left(P_{o} \cdot C+P_{k}\right)
$$

4.68 - the constant that presents the product of the adverse values of coefficients $B, L, S, W$ and $R_{i}$.

Next, a familiar shape of the risk equation applied to the PSH method (3) is wanted.

$$
R o=V \cdot H \cdot F \cdot n
$$

For the adverse factor values, under constant exposure $\left(F_{\text {max }}=5\right)$, the maximum damage value is expected $\left(H_{\max }=15\right)$, so the equation (1a) becomes:

$$
\begin{gathered}
R o=4.68\left(P_{o} \cdot C+P_{k}\right) \cdot 15 \cdot 5 / 15 \cdot 5 \\
R o=0.0624\left(P o \cdot C+P_{k}\right) \cdot 15 \cdot 5
\end{gathered}
$$

For the existing values of probability (3) or the function $f(x)$, the total fire burden can be determined, of the equations (2a) and (3) are leveled and have damage size and frequency eliminated. Then one gets:

$$
P_{o} \cdot C+P_{k}=V_{i} / 0.0624
$$

Tab. 1

Thus calculated total heat burden is a probability that must be combined (multiplied) with the size of the damage and frequency. The size and frequency of exposure can have different values. However, here they will always have the maximum values, 5 and 15 , and the measures factors $(B, L, S, W$ and $R_{i}$ ) will be used to affect the probability of the value, damage or frequency, or, the size of the risk values. The values or, the connection of the probability and the heat burden are provided in the Tab. 1 .

One of the basic steps in the risk evaluation method is the risk valuing. In the method applied here, the results of those values are:

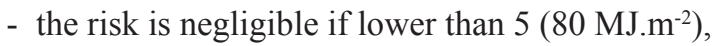

- the risk is low. but important if between 5 and 50,

- the risk is high if between 50 and 500,

- the risk is unacceptable if higher than 500. 
Besides defining the risk level, what must be added to the valuing the risk are the described actions and activities of the individuals, management and community, as well as their behaviour at the certain risk appearance.

The risk evaluation methodology considers that the risk decrease measures are conducted after specifying the risk. The used measures are determined by the factors, the characteristics of the structure, the time until the start of the extinguishing process, the width of the fire sector, the resistance to fire and the circumstances that affect the risk reduction. Calculated risk is, through these factors, reduced or projected to a desired measure.

\section{An example:}

The structure's fire resistance and construction are 9097.5 MJ.m-2. This implies a continual danger frequency $(F=5)$ and the maximum damage $(H=15)$.

This resistance comes down to a probability of the equation 1e of $121.3 \mathrm{MJ} . \mathrm{m}^{-2}$, or $V=7.57$.

The risk, according to the equation (3), is:

$$
R=7.57 \cdot 15 \cdot 5=567.75\left(9098.56 \mathrm{MJ} . \mathrm{m}^{-2}\right)
$$

According to (3), this risk is not accepted as it is too high.

As we are in the projection phase, there is a fire sector reduction possibility up to $1500 \mathrm{~m}^{2}$, so the coefficient $B=0.5$, the fire sector width reduction is up to $20 \mathrm{~m}$, so the coefficient $S=0.77$ and, by using tin storage trunks, the risk reduction coefficient $R_{1}=1$. After these measures, the risk is:

$$
R=567.75 \cdot 0.5 \cdot 0.77 \cdot 1=218.58\left(3502.9{\left.\mathrm{MJ} . \mathrm{m}^{-2}\right)}^{2}\right.
$$

The calculated risk is high, but can be accepted.

\section{The Structure's Content Risk}

There are two kinds of structure content fire risks:

The first kind is the property risk, $R_{i m}$, expressed by the property coefficient $D$, and it depends on the structure's content worth. Its value is between 1 and 3 and it hence expands the risk calculated by the equation $1 \mathrm{~d}$.

$$
R_{\text {im }}=R \cdot D=\cdot 0.0624\left(P_{o} \cdot C+P_{k}\right) \cdot 15 \cdot 5 \cdot D
$$

The previously determined risk is given special importance by this; it expands if the structure is worth more or decreases if the structure is worth less. As the risk in the equation (2a) already presents the middle coefficient level from the table (Macdonald, 2004), $D=1$. That way, the coefficient $D$ would have the double value for the priceless values, and thus expand the risk, while the worthless structure would have the twice lower risk.

\begin{tabular}{|c|c|c|c|}
\hline $\begin{array}{c}\text { Structure's } \\
\text { worth: }\end{array}$ & No value & Has value & Priceless \\
\hline D & 0,5 & 1 & 2 \\
\hline
\end{tabular}

This number corresponds to the number of people simultaneously exposed to the risk in equation 3 , represented by the coefficient " $n$."

Completely the same situation is applicable to the human risk evaluation. The equation 1a regards the combination which has high danger to the humans. This coefficient is marked as $H$ and its value is between 1 and 3 and is calculated in the same way as $D$.

\begin{tabular}{|c|c|c|c|}
\hline $\begin{array}{c}\text { Danger } \\
\text { towards } \\
\text { humans: }\end{array}$ & $\begin{array}{c}\text { No } \\
\text { danger }\end{array}$ & $\begin{array}{c}\text { Danger present, } \\
\text { but people can } \\
\text { rescue themselves }\end{array}$ & $\begin{array}{c}\text { Special } \\
\text { dangers } \\
\text { present }\end{array}$ \\
\hline $\mathrm{H}$ & 1 & 2 & 3 \\
\hline
\end{tabular}

The second coefficient that expands the human risk is the smoke effectiveness coefficient. It is used in the way mentioned before ((Purt, 1972).

The final human risk has the following form:

$R_{l j}=R \cdot H \cdot F=0.0624\left(P_{o} \cdot C+P_{k}\right) \cdot 15 \cdot 5 \cdot H \cdot F$

An example:

The previous example considered a worthless structure (a wooden hut, for example). There are handicapped people there and over $50 \%$ mass of material with toxic combustive products.

The property risk worth is:

$$
R_{\text {im }}=R \cdot D ”=218.58 \cdot 0,5=109.29
$$

And the human risk is:

$$
R_{l j}=R \cdot H \cdot F=218.58 \cdot 2 \cdot 2=874.32
$$

No matter how low the property risk is, such unacceptably high human risk would be crucial for further reduction behaviour.

\section{The Fireman's Risk}

Until now, the property and human fire risks have been defined, but only towards those elements that can be found during work, habitation or any other situation. However, besides them, the firemen involved in extinguishing the fire can be affected by the fire risks. The School's method has been applied to various risk estimates, involving firemen's risk evaluation (Nikolic, 2009) and (Vidakovic, 2011). Parts of the firemen's risk evaluation example, according to (Vidakovic, 2011) are: 


\section{The danger and harm analyses}

Due to a failure at the structure, dangerous material leakage, fire and explosion can occur. Dangerous matter can be flammable, explosive, toxic, etc. Injuries can be mechanical, choking, poisoning, burns and even death.

\section{The risk evaluation}

According to the equation 3 and the method (Nikolic and Gemovic, 2009a; Nikolic and Gemovic, 2009b), the firemen's risk for recognized danger and harm is:

$$
R=V \cdot H \cdot F \cdot n=2.53 \cdot 15 \cdot 2.5 \cdot 2=190
$$

The calculated risk is high and it is necessary to conduct serious measures to reduce it.

\section{The risk reduction measures}

- regular training,

- regular vocational training with stimulation,

- maintaining shape training, psychological and physical readiness,

- accurate and obligatory use of personal and common safety gear,

- procedural behaviour with dangerous and harmful matter.

\section{A new risk calculation - after the measures}

$$
R=V \cdot H \cdot F \cdot n=2.53 \cdot 15 \cdot 2.5 \cdot 2=190
$$

The previous equation shows that the values for the probability, harm and frequency remained the same as in the equation $3 \mathrm{a}$, so the risk remains the same as well.
Unfortunately, the dangers cannot be decreased by any measures and high risk remains present. A fireman's working place is among the rare ones with the high risk.

\section{The measures that maintain the risk at a calculated level}

When a satisfying risk level is accomplished, it is crucial to maintain it on the same level. Not supporting these measures would introduce the increase of the risk.

\section{Conclusion}

There are phases in the risk evaluation process whose order is absolutely unequivocally defined: the description of the process, the dangers, determining the risk, the measures, the risk, and the measures that maintain the risk at a calculated level. All the topics are at an expert level, while the measures are even above it, since they open the space for sublime vocation exhibition. Even in the article (Purt, 1972), the final goal was what level of automatic extinguish process is to be set. What was provided were several levels of possibilities by combining detection, alert and the extinguishing system itself? This article lacks that. Consciously neglected and reserved as a future "treat," not only as a measure, but as the element of determining activities regarding risk values.

The fire risk evaluation method analyses, and then the synthesis in the OSH area, contribute to a better understanding of the quality projecting, deciding, construction and exploitation of structures of all kinds.

The offered approach secures a unique evaluation of all existing risks. It is important to represent all risks and their values quantitatively, allowing clear expression of risks size during their comparison.

\section{References}

GRETENER, M. (1973). Determination des measures de protection decoulant de l,evaluation du danger potenciel d,incendie. Berne.

HARMS-RINGDAHL, L. (2001). Safety analysis, principles and practice in occupational safety. CRC Press.

MACDONALD, D. (2004). Practical Machinery Safety, Integra Software Services Pvt. Ltd, Pondicherry, India.

NIKOLIC, B. (2009). Assessment of Risk for the Professional Role of Firefighter - Leader of smoke control team. In: Proceedings of the Risk Assessment Conference. Kopaonik, Serbia, 2009.

NIKOLIC, B., RUZIC - DIMITRIJEVIC, Ljiljana (2009). Risk Assessment of Information Technology System. Informing Science and Information Technology. 2009, Vol. 6. 
NIKOLIC, B., GEMOVIC, B. (2009a). The Method of Risk Assessment at Workplace and Working Environment in an Example of Metal Mechanical Processing Selection of a Factory. In Proceedings of the International Symposium “Interdisciplinary Regional Research". 2009, Romania.

NIKOLIC, B., GEMOVIC, B. (2009b). Application of Risk Assessment method in Workplace and Working Environment. Safety and Health in Work and Environmental Protection, Banja Luka 2009 pp. 49 -57.

NIKOLIC, B. (2010). Comparative Analysis of the Analysis, Evaluation and Assessment of Risk in the Field of Fire Protection. In: Proceedings of the $2^{\text {nd }}$ International Conference on Fire and Explosion Protection. Novi Sad, Serbia, 2010.

PURT, Gustav A. (1972). The Evaluation of the Fire Risk as a Basis for Planning Automatic Fire Protection Systems. Fire Technology, 1972, Vol. 8, No. 4, pp. 291-300.

TAKALA, J. (1998). Global estimates of fatal occupational accidents. In: Proceedings of the Sixteenth International Conference of Labour Statisticians, International Labour Office, Geneva.

VIDAKOVIC, D. (2011). Risk Assessment for Fire and Rescuing Centre Bar. Specialist paper, Higher Technical School of Professional Studies. 2011, Novi Sad, Serbia. 